\title{
Investigating Female Students' Stem-Related Attitudes, Engagement and Work-Intentions When Involved in a University Workshop Initiative
}

\author{
Tasos Barkatsas ${ }^{1}$, Grant Cooper, Patricia McLaughlin \\ RMIT University, Australia
}

\begin{abstract}
Encouraging females to engage in and pursue Science, Technology, Engineering and Mathematics (STEM) education and vocations are key priorities for stakeholders and primary aims of the Australian Government-funded STEM in Situ (WISE 2016-18) project. Using a researcher-designed student survey by two of the authors, this article reports on the STEM-related attitudes, engagement and vocational intentions of female students involved in the project. The research survey developed for the project collected data in 2017-8 from 221 female students in Years 5-9 (11 to 16 years of age) from various public schools in Australia. Factor analytic and repeated measures t-tests data analysis techniques were used to explore the factor structure of the survey items and to examine students'STEM-related attitudes, engagement and future work intentions both before and after their participation in the STEM in Situ project. The findings highlight the outcomes of the STEM in Situ workshops upon female students attitudes and engagements with STEM careers. The findings have the potential to inform future policies related to STEM interventions for young women.
\end{abstract}

Keywords: STEM, integration, iSTEM, integrated STEM, elementary STEM

\section{Background}

Science, Technology, Engineering and Mathematics (STEM) education has been described as a global education reform movement (GERM), fuelled in part by concerns about the capacity of various countries to innovate, compete globally and address forecasted shortages in human capital (Carter, 2018). Similar to other countries, concerns about these issues have been voiced in Australia. For instance, Marginson, Tytler, Freeman and Roberts (2013) stated that "In world terms, Australia is positioned not far below the top group but lacks the national urgency found in the United States, East Asia and much of Western Europe, and runs the risk of being left behind" (p. 12). Frequently, an economic imperative has been emphasised in discussions about the importance of STEM education, especially in policy documents and other-related literature (Office of the Chief Scientist, 2016; Price Waterhouse Coopers, 2015). Such an economic imperative refers to supply and demand of workers, and the skills shortfall of STEM-related occupations (Archer et al., 2013). This is reinforced by forecasts that STEM employment will grow 50\% faster than other jobs with considerable growth in professional, scientific and health care roles (Hobbs, Clark, \& Plant, 2018). Beyond an economic imperative, it could be argued that STEM-related literacies are also important in terms of a social imperative, with implications for possible innovation that may help address significant challenges such as climate change, an over-dependence on fossil fuels, and biodiversity loss.

${ }^{1}$ Corresponding author: Tasos Barkatsas, School of Education, RMIT University, Australia PO Box 71, Bundoora, VIC 3083 Australia, E-mail: tasos. barkatsas@rmit.edu.au

Barkatas, T., Cooper, G., \& McLaughlin, P. (2019). Investigating female students' STEM-related attitudes, engagement and work-intentions when involved in a university workshop initiative. Journal of Research in STEM Education, 5(1), 60-74. 
The term "STEM Education" itself is a contested notion, with several (sometimes conflicting) definitions and ways of being operationalised. Portz (2015) even goes so far to say that STEM education has an "identity crisis" (p. 2). Although there are differences in how STEM education has been defined, in the literature at least, there are some commonalities in its conceptualisation. For example, Radloff and Guzey (2016) identified three common features in the research. First, there is an emphasis on the interconnected nature of disciplines.. An example of such research is that of Vasquez (2015), who conceptualised STEM education on a continuum from a discrete disciplinary approach (akin to S-T-E-M) towards a more integrated, trans-disciplinary approach at the opposite end of this spectrum (STEM). According to Vasquez (2015), genuinely trans-disciplinary STEM education requires that students undertake real world-problems and apply knowledge and skills from different STEM disciplines. The second consistency that Radloff and Guzey discussed was the connectivity emphasised among school communities and industry and the focus on generic competences (e.g., problem solving, working in teams, creativity). The third commonality is the notion that STEM education is commonly tailored to stakeholders' needs and contexts. Awareness of context means schools are operationalising STEM to meet the needs of students and give them access to innovative technologies and specific educator expertise in schools.

As nations strive to reform the delivery and relevance of STEM education, a consistent and ongoing challenge is addressing the underrepresentation of particular student groups. There are concerns about the engagement of females in STEM. There is evidence to indicate the engagement, participation and performance of females in STEM is in decline both at tertiary and senior secondary levels of education (Kennedy, Lyons, \& Quinn, 2014; Timms, Moyle, Weldon, \& Mitchell, 2018; Weber, 2012). As noted by several researchers in this field, without a diverse female-targeted STEM pipeline attempts to change this situation will be marginal (Marginson et al., 2013; Tytler, Osborne, Williams, Tytler \& Clark, 2008; Watt, 2016). A pipeline implies a flow of engaged students in primary school leading to participation of students in secondary and senior-secondary STEM subjects. This in turn means skilled students are retained into post-school STEM learning, including into teacher education courses and also onto STEM-related careers. A longer-term key benefit of a female STEM pipeline is building the flow of STEM-literate parents who pass on curiosity and engagement in STEM to the next generation of women.

Many studies have highlighted the role of identity in STEM learning and the need to address this problem by exposing female students to role models, collaborative STEM experiences, opportunities that match their interests, and mentoring that encourages STEM identities (Archer et al., 2013; Hobbs et al., 2017; Timms et al., 2018). How an individual sees him or her selfherself has been shown to effect and influence general academic engagement (Matthews, Banerjee, \& Lauermann, 2014), performance in specific disciplines (Kozoll \& Osbourne, 2004), and to the pursuit of future careers (Perez, Cromley, \& Kaplan, 2013).

Polman and Miller (2010) described STEM identity as the ability of individuals to see themselves as the kind of people who could be legitimate participants in STEM through their interests, abilities, race, gender, and cultures. Other researchers note the role of experts or parents in influencing positive STEM outcomes (Archer et al., 2010; Nadelson et al., 2013). Different gender expectations also build identity when it comes to STEM and these expectations contribute to an identity that sees engaging in STEM as "clever and brainy" and not "caring or nurturing," the latter being traits that are typically seen to be more appealing to girls (Wang \& Degol, 2013).

Recent research on STEM identities has highlighted the importance of STEM identity in female students and the development of that identity into future STEM careers. Of interest is the importance of social identity amongst high achieving female students. As Kim, Sinatra, and Seyranian (2018) noted: 
Many young girls do not feel positive about their own abilities or their potential for success in STEM. Social identity theory suggests that individuals are driven by a need for positive self-esteem. STEM fields are making it challenging for women to see themselves in a positive light. They are, in fact, often doing the opposite and diminishing positive self-esteem. This is even the case for young women who earn good grades in STEM courses or are deemed gifted. (p. 613)

To identify with STEM, and thus pursue studies and careers in STEM, the STEM learning environment needs to convey messages of welcome for young women. Evidence exists that where programmes encourage interest, positive identity and attitudes towards STEM, positive changes in terms of engagement and interest can be developed by young females (Metcalf, 2013; Naizer, Hawthorne, \& Henley, 2014). The influence of peers has also been found to be important in intentions to pursue STEM careers (Leaper, Farkas, \& Brown, 2012). When young women were encouraged to be part of a STEM "in-group", engagement and interest also grew (Reid \& Roberts, 2006). These studies indicate that engaging in STEM for young women is related to social identity as well as selfidentity.

As part of any reform agenda, stakeholders must address cultural, institutional and organisational factors that discourage girls and women from studying STEM and choosing careers in those fields, particularly in areas of significant under-representation such as physics and engineering. Attempting to ascertain the benefits of interventions that address some of these systemic barriers, the researchers in this study designed a program targeting secondary female students (11-16 years of age). This involved a series of workshops and mentoring activities that provided the female students with hands-on experiences in STEM-related activities and exposure to the creative possibilities of such disciplines.

\section{Context of the Study}

\section{The STEM in Situ Project}

The Women in STEM (WISE)- STEM in Situ project was a nationally funded Australian Government initiative which, over a two-year period, introduced 221 female students aged between 11 and 16 years (grades years 5-9), including those from low socio-economic and Indigenous backgrounds, to STEM workshops in technology-rich facilities at a local university. The female students came from twelve schools in the northern and western suburbs of a major city in Australia, up to 25 kilometres distance from the university.

Emphasizing STEM skills in creativity, design, entrepreneurship, problem solving, adaptive thinking, digital literacy and technology-confidence, the project attempted to build the students' STEM self-identity so they could be creators of their own futures. Over four workshop days per school term (totalling of sixteen days) the students explored STEM skills and knowledge across many industries as diverse as: fashion, virtual reality, additive manufacturing, nanotechnology and robotics; in emerging growth industries; and in entrepreneurial opportunities. This involved interactive talks and maker workshops. The female students also had opportunities to undertake group work with tertiary-employed female STEM leaders. Within the workshops, the female students were in groups of mixed ages, abilities and schools. Workshop leaders, technicians and mentors were unaware of the backgrounds or previous STEM understandings of the female students prior to workshop participation.

The STEM in Situ project utilized the STEMTAS survey, which was adapted from the 
Mathematics and Technology Attitudes Scale (MTAS) developed by Pierce, Stacey and Barkatsas (2007). The survey has been used extensively to examine the role of the affective domain in learning mathematics with technology. According to the scale developers, MTAS can be used in schools to track changes in the attitudes and engagement of students in their learning of mathematics. It was based on the work of McLeod (1992), who described the affective domain as being composed of three major constructs - beliefs, attitudes, and emotions - with each representing "increased levels of affective involvement, decreased levels of cognitive involvement, increasing levels of intensity of response, and decreasing levels of response stability" (p. 579).

Student engagement is an important goal for education (Marks, 2000). Fredricks, Blumenfeld, and Paris (2004) note that school engagement is a concept that is malleable, responsive to contextual features and amenable to environmental change. They claim that engagement is a multidimensional concept or a "meta" construct. They proposed the following three dimensions: behavioural engagement, which draws on student participation, emotional engagement, encompassing both positive and negative reactions to staff and the school in general, and cognitive engagement, which draws on the principle of students making an investment in learning (Fredricks et al., 2004). Only two of the dimensions of this framework, that is, behavioural engagement and emotional engagement were incorporated into the STEMTAS instrument used in this study. The cognitive engagement dimension was not investigated in this study.

\section{Measuring Intentions and Attitudes to STEM-Related Future Learning and Careers}

Of key interest to the researchers was the female students' attitudes and intentions to participate in STEM-related learning and careers as a result of the STEM in Situ workshops. Research examining the link between intention and behaviour has its origins in Expectancy-Value Theory (EVT) and is commonly used to examine the beliefs of why individuals choose one behaviour over another (Porter \& Lawler, 1968). Intentions are formed by several beliefs that represent the perceptions that people have about a behaviour including its likely consequences, the normative expectations of others, and the likely barriers of performing a particular behaviour (Ajzen, 2005). A salient predictor of intentions (and future behaviour) is attitude (Kraft, Rise, Sutton \& Røysamb, 2005). Attitude is a key human motivator and it can be viewed as a construct that influences the intensity and direction of a behaviour (Ajzen, 2005). Considering the former, eliciting students' intentions and attitudes to future careers in STEM-related fields has the potential to offer insights into participants' desired future pathways and trajectories.

\section{Research Methods}

\section{Participants}

The participants in the project were 221 (years 5-9) female students from government schools in a major city in Australia. All of the female students were aged between 11 and 16 years and were in primary and secondary schools in the western and northern suburbs of Melbourne. The female students attended schools that were geographically located in a range of socio-economic regions as measured by Socio-Economic Indexes for Areas (SEIFA) index. The schools were located in local council regions ranging between 951 deciles (relative disadvantage) to 1059 deciles (relative advantage) on the SEIFA scale (Australian Bureau of Statistics, 2018).

The guidelines for participation in the STEM workshops did not specify how female students at each school were to be selected for participation. As a result, participation in the workshops was decided by the administrators and the teachers at each school. Some participating schools sent all the female students from a particular grade level; a number of schools sent female students who had 
shown some interest in STEM determined by teacher observation; and some schools decided to use an expression of interest strategy based selection on a "first come basis" of participation.

\section{Data Collection Instrument}

A survey, which included the STEMTAS and the Attitudes to Further Learning in STEM and STEM Career survey, was administered at the beginning of the first day of workshops and again on the last day of workshops, which spanned a period of two to four weeks per school group. The survey was completed anonymously, and students and their parents were made aware of the purpose of the survey via ethics and school consents. Sixteen workshop days were held each year The research study used a 36-item research instrument consisting of two sections:

The STEM Technology Attitudes Survey (STEMTAS).

A Likert-type scoring format was used for each of five subscales (items 1-20):

(i) STEM confidence [STEMC].

(ii) Confidence with digital technology [TC].

(iii) Attitude to learning STEM with digital technology [STEMT].

(iv) Affective engagement $[\mathrm{AE}]$.

(v) Behavioral engagement [BE].

Students were asked to indicate the extent of their agreement with each statement on a fivepoint Likert scale from strongly agree to strongly disagree (scored from 5 to 1 ) for sub scales (i)-(iv). A different but similar response set was used for the BE subscale. Students are asked to indicate the frequency of occurrence of different behaviors. Again, a five-point system was used - nearly always, usually, about half of the time, occasionally, hardly ever (scored from 5 to 1).

The STEMTAS subscales can be defined as follows: STEM Confidence [STEMC]: students' perception of their ability to attain good results and their assurance that they can handle difficulties in STEM subjects; Confidence with Digital Technology [TC]: technology confidence as evidenced by students who feel self-assured in operating computers, believe they can master digital technology procedures required of them, are more sure of their answers when supported by a computer, and in cases of mistakes in digital technology work are confident of resolving the problem themselves; Attitudes to Learning STEM with Digital Technology (STEMT): students believe that the use of digital technology interfaces enhances STEM learning by the provision of many examples, find notemaking helpful to augment screen based information; Affective Engagement [AE]: how students feel about mathematics and Behavioral Engagement [BE]: how students behave in learning STEM-related subjects.

\section{(2) The Attitudes to Further Learning in STEM and Intentions of a STEM Career survey}

A key aim of Section 2 (items 21-36) of the survey instrument was to elicit students' intentions about STEM-related future learning and careers. Semantic differentials using five-point scales were used to elicit Attitudes to further learning in STEM (e.g., I believe further learning in STEM will be [useless-worthwhile]). Attitudes to a STEM career were also elicited (e.g., I believe a STEM career in the future will be [bad for me-good for me]). Experiential items (how it feels to perform the behaviour [e.g., studying further learning in STEM will be unpleasant/pleasant]) and instrumental items (whether the behaviour achieves something [e.g., I believe further learning in STEM will be useless/worthwhile]) were included. Also, Likert-type format was used to elicit participants' Intentions to study STEM at university and Intentions to work in a STEM-related field in the future (1-strongly disagree to 5-strongly agree). 


\section{Data analysis}

An initial data screening was carried out to test for univariate normality, multivariate outliers (Mahalanobis' distance criterion), homogeneity of variance-covariance matrices (using Box's M tests) and multicollinearity and singularity (tested in the MANOVA analysis). Descriptive statistics normality tests (normal probability plot, detrended normal plot, Kolmogorov-Smirnov statistic with a Lilliefors significance level, Shapiro-Wilks statistic, skewness and kurtosis) showed that assumptions of univariate normality were not violated (Tabachnick \& Fidell, 1996). Univariate and multivariate distributions were examined for potential outliers. As a result, four students were eliminated from the consequent analyses, resulting in a final sample size of 217 students. Box's M Test of homogeneity of the variance-covariance matrices (which tests the null hypothesis that the observed covariance matrices of the dependent variables are equal across groups) was not significant at the 0.001 alpha level and we therefore concluded that homogeneity of variance may be assumed (Tabachnick \& Fidell, 1996). The items in each of the two sections of the survey were subjected to an Exploratory Factor Analysis (EFA). Reliability tests were also conducted and a repeated measures (paired t-test) was used to investigate statistically significant differences between the pretest and the posttest variables.

\section{Exploratory Factor Analysis}

(1) STEMTAS (items 1-20)

A Principal Component Analysis (PCA) with a Varimax rotation from students' pretest responses to the 20 Section 1 (STEMTAS) survey items indicated that the data satisfied the underlying assumptions of the factor analysis (Table 1). The data revealed that together, the five factors (each with eigenvalue greater than 1) explained $62.1 \%$ of the variance, with $32.5 \%$ attributed to the first factor - STEM confidence. Further, according to Coakes and Steed (1999), if the Kaiser-MeyerOlkin (KMO) measure of sampling adequacy is greater than 0.6 and the Bartlett's test of sphericity (BTS) is significant then factorability of the correlation matrix is assumed. A matrix that is factorable should include several sizable correlations. The Kaiser-Meyer-Olkin (KMO) measure of sampling adequacy in this study is greater than 0.81 and the Bartlett's test of sphericity (BTS) is significant at 0.001 level, so factorability of the correlation matrix has been assumed. Reliability analysis yield satisfactory Cronbach's alpha values for each factor: Factor 1, 0.97; Factor 2, 0.93; Factor 3, 0.88; Factor 4, 0.80 and Factor 5, 0.70. These values indicate a moderate to strong degree of internal consistency in each factor (Hair, Black, Babin and Anderson, 2014). 
Table 1. Rotated Component Matrix (items 1-20). Extraction method: Principal Component Analysis, Rotation method: Varimax with Kaiser Normalization

\begin{tabular}{|c|c|c|c|c|c|}
\hline & \multicolumn{5}{|c|}{ Component } \\
\hline & 1 & 2 & 3 & 4 & 5 \\
\hline Q9. I have a 'STEM' mind & .767 & & & & \\
\hline Q10. Overall, I can get good results in STEM & .753 & & & & \\
\hline $\begin{array}{l}\text { Q16. I get a sense of satisfaction when I solve STEM } \\
\text { problems }\end{array}$ & .720 & & & & \\
\hline Q1.1 I know I can handle difficulties in STEM & .707 & & & & \\
\hline Q12. I am confident with STEM & .613 & & & & \\
\hline $\begin{array}{l}\text { Q19. STEM is more interesting when using information/ } \\
\text { digital technology }\end{array}$ & & .863 & & & \\
\hline $\begin{array}{l}\text { Q17. I like using information/digital technology for } \\
\text { STEM }\end{array}$ & & .750 & & & \\
\hline $\begin{array}{l}\text { Q18. Using information/digital technology in STEM is } \\
\text { worth the extra effort }\end{array}$ & & .674 & & & \\
\hline $\begin{array}{l}\text { Q20. Information/digital technology help me learn STEM } \\
\text { better }\end{array}$ & & .642 & & & \\
\hline $\begin{array}{l}\text { Q7. I can fix a lot of information/digital technology } \\
\text { problems }\end{array}$ & & & .760 & & \\
\hline Q5. I am good at using information/digital technology & & & .733 & & \\
\hline $\begin{array}{l}\text { Q6. I am good at using things like ipods, ipads, bluetooth, } \\
\text { mobile phones and the internet }\end{array}$ & & & .727 & & \\
\hline Q4. If I can’t do a problem, I keep trying different ideas & & & & .761 & \\
\hline Q3. If I make mistakes, I work until I have corrected them & & & & .752 & \\
\hline Q1. I concentrate hard in STEM & & & & .632 & \\
\hline Q2. I try to answer questions the teacher asks & & & & .546 & \\
\hline Q14. In STEM you get rewards for your effort & & & & & .624 \\
\hline Q15. Learning STEM is enjoyable & & & & & .556 \\
\hline Q13. I am interested to learn new things in STEM & & & & & .472 \\
\hline
\end{tabular}

The naming of the five factors was guided by the relevant literature and the nature of the questionnaire items associated with each factor. This resulted in the following five factors (F1-F5):

- F1: STEM Confidence (STEMC)

- F2: Attitudes to Learning STEM with Digital Technology (STEMT)

- F3: Confidence with Digital Technology (TC)

- F4: Behavioral Engagement (BE)

- F5: Affective Engagement (AE)

The first factor (STEMC) consisted of five items, which examined students' STEM confidence. One item from the affective engagement (AE) subscale was loaded with this factor. A plausible explanation is that it is a sample-specific outcome. The 2nd factor (STEMLT) consisted of four items, which examined students' Attitudes to Learning STEM with Digital Technology. The $3^{\text {rd }}$ factor consisted of four items, which examined students' Confidence with Digital Technology (TC). Factor 5 consisted of three items, which examined students' Behavioral Engagement (BE).

(2) STEM-related intentions and attitudes to future learning and careers (items 21-36) 
A Maximum Likelihood extraction method and a Varimax rotation (Tabachnick \& Fidell, (1996) was used in the survey items 21-36 (Table 2). Two factors (each with eigenvalue greater than 1) explained $69.98 \%$ of the variance, with $54.65 \%$ attributed to the first factor - Intentions to continue a STEM-related trajectory. For this part of the study, the KMO $=0.89$ and BTS was significant $(p<0.01)$, so factorability of the correlation matrix is assumed. Cronbach's alpha indicated a strong degree of internal consistency in each factor: Factor 1, 0.96 and Factor 2, 0.84.

Table 2 . Rotated Factor Matrix (items 21-36). Extraction Method: Maximum Likelihood, Rotation Method: Varimax with Kaiser Normalization.

\begin{tabular}{lll}
\hline & Factor & \\
\cline { 2 - 3 } & & 1 \\
\hline Q36. I plan to work in a STEM-related field in the future & .934 \\
Q33. I expect to work in a STEM-related field in the future & .909 \\
Q31. I intend to study a STEM-related degree at university & .909 \\
Q35. I intend to work in a STEM-related field in the future & .904 \\
Q32. I plan to study a STEM-related degree at university & .891 \\
Q29. I expect to study a STEM-related degree at university & .883 & .847 \\
Q34. I want to work in a STEM-related field in the future & .812 & .896 \\
Q30. I want to study a STEM-related degree at university & & .851 \\
Q27. A STEM career in the future will be (Unpleasant/Pleasant) & .569 \\
Q28. I believe a STEM career in the future will be (Unenjoyable/Enjoyable) & \\
Q24. I believe further learning in STEM will be (Unenjoyable/Enjoyable) & \\
Q23. Studying further learning in STEM will be (Unpleasant/Pleasant) & \\
Q26. I believe a STEM career in the future will be (Useless/Worthwhile) & & .557 \\
\hline
\end{tabular}

As with Section 1, the naming of the two factors was guided by relevant literature and the nature of the questionnaire items associated with each factor:

- F1: Intentions to continue a STEM-related trajectory (STEMIT)

Shown in Table 2, the first factor (STEMIT) consisted of eight items, eliciting students' intentions to continue a STEM-related trajectory, inclusive of STEM study and/or pathways. This measure is reflective of students' intentions to stay in the so-called 'STEM pipeline'.

- F2: Attitude to continue a STEM-related trajectory (STEMAT)

The second factor (STEMAT) included five items, examining students' attitude to continuing along a STEM pathway. Such an attitude is an overall positive evaluation of future STEM study and work options.

\section{Repeated Measures (Paired t-test)}

The existence of statistically significant differences on the sample's pretest and the posttest scores was investigated by a Wilcoxon signed-rank repeated measures t-test (Coakes \& Steed, 1996). By checking the t-values and the two-tail significance, statistically significant differences were found for the following items in the STEMTAS section of the survey (items 1-20):

- I try to answer questions the teacher asks $[z=-2.191, p<.05]$

- I am good at using information/digital technology $[\mathrm{z}=-2.227, \mathrm{p}<.05]$

- I can fix a lot of information/digital technology problems $[z=-3.904, p<.05$

- Overall, I get good results in STEM $[\mathrm{z}=-2.502, \mathrm{p}<.05]$ 
- I like using information/digital technology for STEM $[z=-1.990, p<.01]$

- STEM is more interesting when using information/digital technology $[\mathrm{z}=-2.845, \mathrm{p}<$ $.01]$

- Information/digital technology help me learn STEM better $[\mathrm{z}=-2.258, \mathrm{p}<.05]$

Statistically significant differences in the means of pretest and posttest scores were found for all STEMT items, 2 Confidence with Technology items and 1 affective engagement item. No statistically significant differences were found for any of the STEM-related intentions and attitudes to future learning and careers items. The pre-directional responses of the pretest and the posttest mean scores for the STEMTAS items are shown in Figure 1. For most pretest items, the mean scores were greater than 4.0 and most posttest items the mean scores were greater than 4.2 . The mean pretest score was 4.2 , and the mean posttest score was 4.3 . For $90 \%$ of the items the mean scores for the posttest were greater than mean scores for the pretest. The pretest mean scores or items 6 and 13 were greater than their posttest mean scores. Item 7 had the smallest mean score and item 13 the largest mean score. 


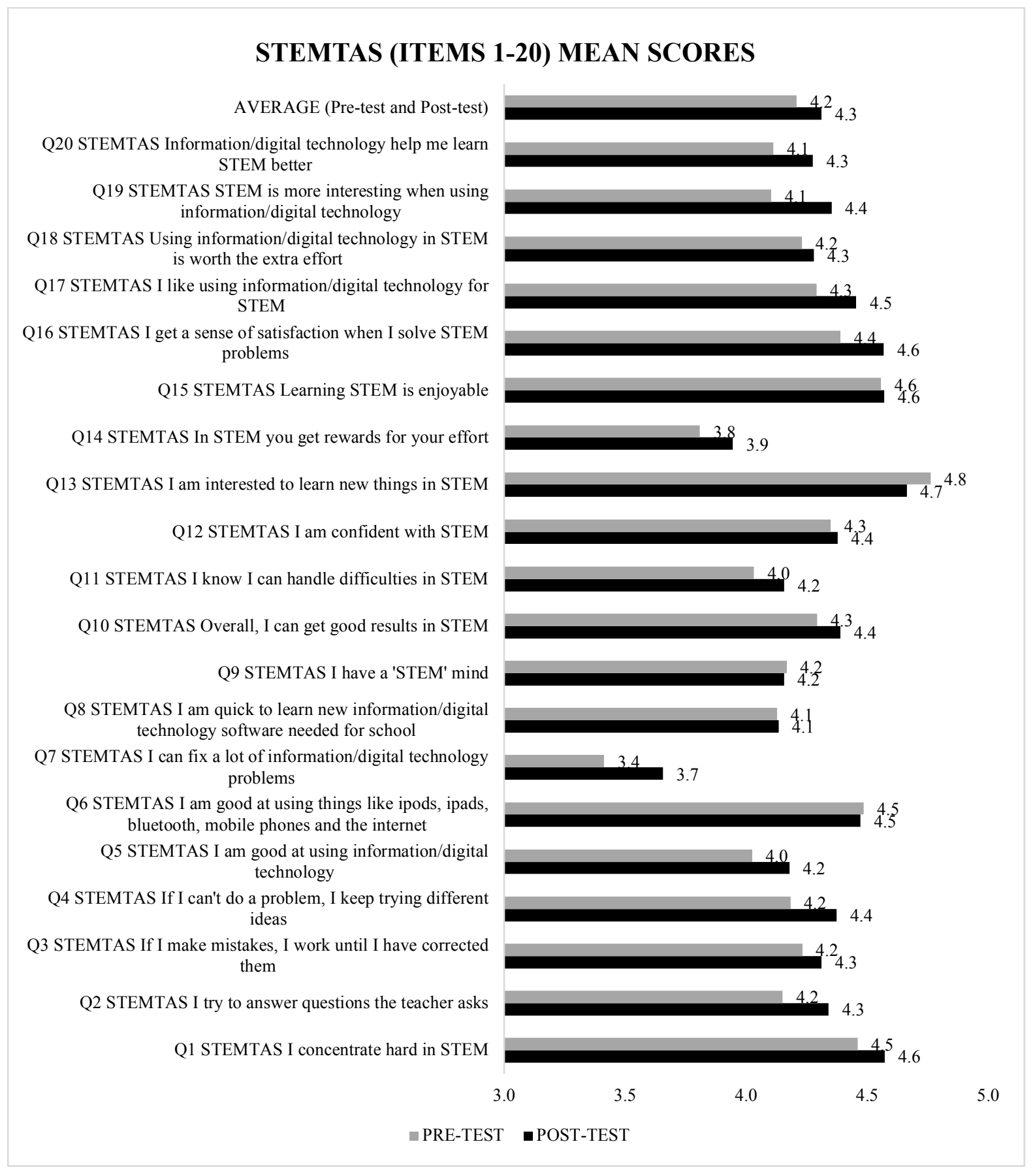

Figure 1. STEMTAS pretest and posttest mean scores.

Overall, the pre and posttest averages for the items in Section 2 (Figure 2) were equal. Examining this data further, approximately $37 \%$ of the items in this part of the study indicated that posttest scores were slightly lower (none were statistically significantly lower) than pretest measuring. Approximately the same number of items $(\approx 37 \%)$ indicated no change between pre and post testing. Conversely, $25 \%$ of items were higher in posttest measures than the pretest examination, although yet again, none of the t-tests indicated significantly different results $(p>.05)$. 


\section{Attitudes and intentions of future STEM learning/career (Items 21-}

36)

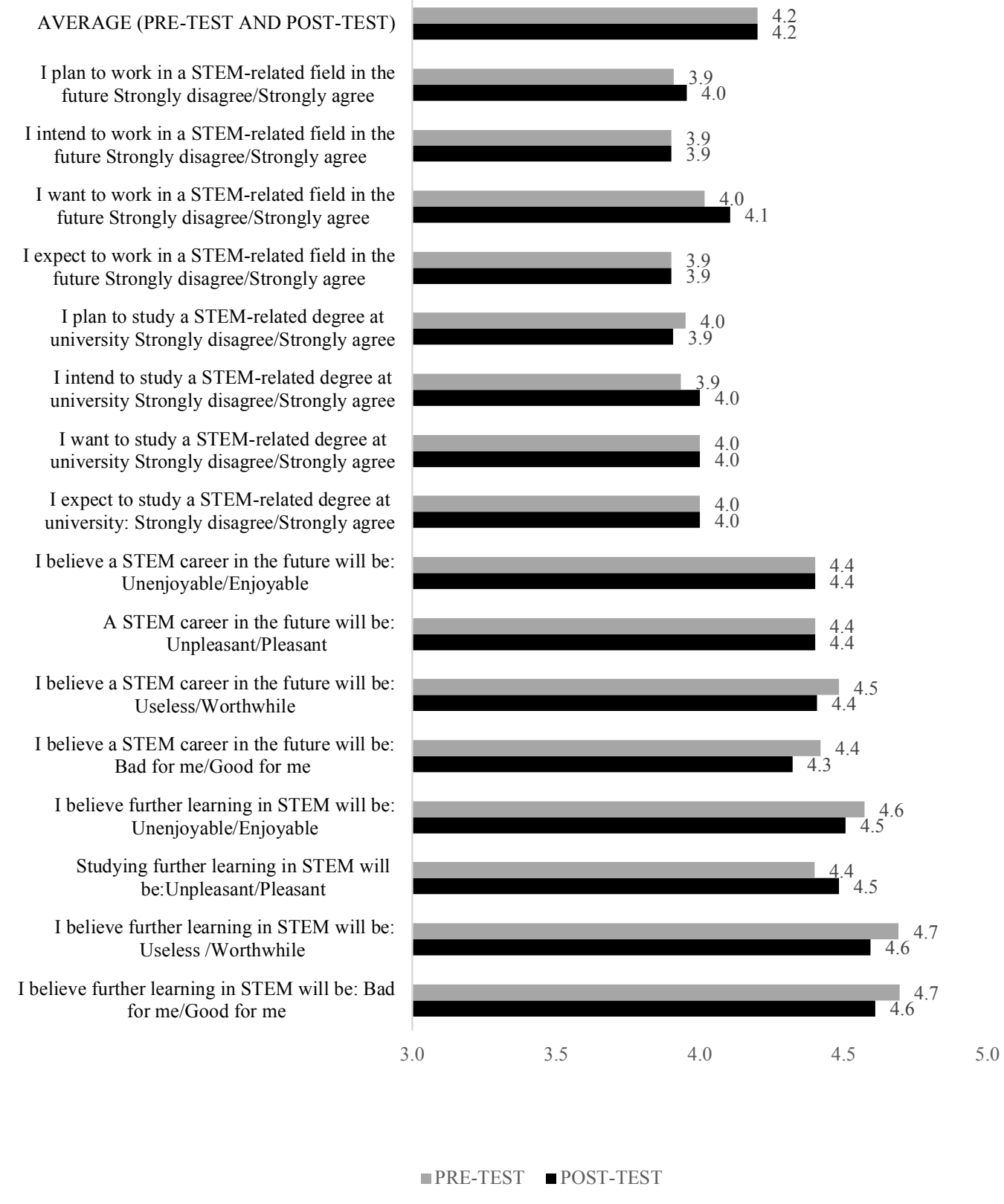

Figure 2. Pretest and posttest scores of STEM-related attitudes to future learning and intentions of STEM careers.

\section{Discussion}

An essential element of the STEM discourse internationally is how to cater effectively for the needs and barriers facing under-represented groups in their study of, and vocational participation in STEM. In male dominated areas of STEM (e.g. physics, engineering, digital technologies), reform agendas need to challenge cultural, institutional and organisational factors that discourage females from studying STEM and choosing careers in those fields. Student experiences that challenge covert 
and overt norms about who belongs and who should participate STEM disciplines is crucial, and hence the program of interest in this study was a modest attempt to challenge such assumptions. Aligning with the research discussed earlier about the importance of identity in STEM learning (Kozoll \& Osbourne, 2004; Matthews et al., 2014), STEM in-Situ was designed to expose female students to role models, collaborative STEM experiences, opportunities that match their interests, and mentoring that encourages STEM identities. Salient elements of such identities are inclusive of students'- beliefs, attitudes and intentions to continue (or discontinue) their STEM pathways.

The development of the STEMTAS instrument was based on the assumption that it would measure affective changes in participants. The results of the STEMTAS items (items 1-20) indicated that statistically significant differences in the means of pretest and posttest were found for all STEMT items, 2 Confidence with Technology items and 1 Affective engagement item. It appears that the students' attitudes to learning STEM with digital technology were impacted on positively. Such attitudes have the potential to impact students' STEM learning participation and learning outcomes although such associations need further research in this context before one could reasonable claim such relationships.

It is important to point out that this research is exploratory in nature and in a relatively early phase of development. There is the intention to validate STEMTAS by Confirmatory Factor Analysis (CFA) and Structural Equation Modelling (SEM) techniques through studies with various samples, which will include both male and female students from different countries, school sectors and cultural contexts. The results from this study provide preliminary positive confirmation of the validity and reliability of the survey.

There were no significant differences between the pretest and the posttest mean scores in Section 2: Attitudes to learning and career intentions (items 21-36) of the survey instrument. This is consistent with findings reported by Reid and Roberts (2006) in relation to pre and posttest scores in intervention programs. However, it could be argued, as Reid and Roberts suggest, the constructs of future study intentions, attitudes and STEM engagement form over a relatively long-time span. Hence, the potential to see significant differences in pre and post testing does not necessarily indicate the efficacy of the intervention. Projects such as the STEM in Situ initiative offer the potential for students to experience an 'episodic STEM moment'- a salient experience that students reflect on in the future as they consider their future study and work pathways. The impact of a recalled episodic STEM moment may not occur for some time, it is possible that the value of such an experience is not realised until several years into the future, potentially when the female students are making a pathway decision about their education or career.

Ideally programs such as STEM in Situ should complement a home and school environment that places value upon the learning of STEM knowledge and skills. Adamuti-Trache and Andres (2008) note that parents influence their children's academic choices and, in doing so have the potential to encourage them toward STEM-related subjects. Beyond parental influence, it is important for stakeholders to consider and address structural barriers, a significant challenge for educators appears to be the design and implementation of a STEM program that meets the diverse needs of students, particularly for under-represented cohorts, including females in subjects such as physics and engineering. Overall, this workshop initiative (STEM in situ) provided a space for participants to consider their future STEM trajectories, offering chances to collaborate with female peers who share similar aspirations. Such programs are important in promoting and fostering an environment that places value on the learning and participation of STEM education in students' lives.

Students' STEM-related beliefs, attitudes and intentions have been conceptualised in this study as salient components of their identities - as the ability of individuals to see themselves as the kind of people who could be legitimate participants in STEM through their interests, abilities, 
race, gender, and cultures (Polman \& Miller, 2010). As noted previously, Kim etal. (2018) stated that "many young girls do not feel positive about their own abilities or their potential for success in STEM" (p. 613). While this specific project is in its infancy, there are encouraging signs that STEM in Situ has had positive impacts on different elements of students' STEM literacies. Nevertheless, it is important to remember the relatively modest scope of this initiative and the need for a much larger suite of resources and programs dedicated to addressing the systemic factors that negatively impact the potential of females studying STEM and participating in related careers.

\section{Conclusion}

Evidence indicates that female engagement, participation and performance in STEM are in decline both at tertiary and senior secondary levels of schooling (Office of Chief Scientist, 2016). This study investigated STEM-related attitudes, engagement and vocational intentions of secondary female students. The study examined the responses of female students who participated in the STEM in Situ (WISE 2016-18) project. The aims of the research study were to measure the factorial structure of the research survey used in this research and to examine differences between students' pretest and posttest attitudes toward STEM, STEM confidence, engagement with STEM and their STEM-related future learning and careers. The study indicates there were not significant differences in many of the pre and posttest results, but there were significant differences regarding students' use and confidence with digital technologies. However, constructs of future study intentions, attitudes and STEM engagement form over a relatively long-time span. Hence, the potential to see significant differences does not necessarily indicate the full potential of the intervention. Programs such as STEM in situ do provide the opportunity for students to experience episodic STEM moments, now or into the future. Such intervention environments have the capacity to promote and foster engagement and interest in STEM and should be considered in future STEM initiatives to change longer-term outcomes.

A second longer term consideration is the development of school/university partnerships to promote female engagement and future intentions in STEM. The STEM in Situ model allowed stakeholders (e.g., technicians, pre and in-service teachers, students, mentors) to come together and engage in STEM workshops as a collective team in a university/school partnership. This opportunity indicates the potential for future adoption of STEM interventions, in particular the exposure to STEM equipment and resources not utilised or available in school facilities. Such partnerships may also build longer term outcomes not measurable in this study. The importance of developing female STEMidentity and building a female STEM pipeline to achieve reform in STEM participation, engagement and long-term career aspirations are key motivators in interventions such as that described in this study. Continued support for this type of intervention has the potential to achieve long term change for the benefit of more diverse, inclusive and creative STEM spaces.

\section{References}

Adamuti-Trache, M., \& Andres, L. (2008). Embarking on and persisting in scientific fields of study: Cultural capital, gender, and curriculum along the science pipeline. International Journal of Science Education, 30(12), 1557-1584. https://doi.org/10.1080/09500690701324208

Ajzen, I. (2005). Attitudes, personality, and behavior (1st ed.). Maidenhead, England: Open University Press.

Archer, L., DeWitt, J., Osborne, J., Dillon, J., Willis, B., \& Wong, B. (2010). "Doing” science versus “being” a scientist: Examining 10/11-year-old schoolchildren's constructions of science through the lens of identity. Science Education, 94(4), 617-639.

Archer, L., DeWitt, J., Osborne, J., Dillon, J., Willis, B., \& Wong, B. (2013). 'Not girly, not sexy, not glamorous': Primary school girls' and parents' constructions of science aspirations. Pedagogy, Culture \& 
Society, 21(1), 171-194.

Australian Bureau of Statistics. (2018). Socio-Economic Indexes for Areas (SEIFA). $\quad$ Retrieved from https:/www.abs.gov.au/AUSSTATS/abs@.nsf/ allprimarymainfeatures/09D68973F50B8258CA2573F0000DA181?opendocument

Carter, L. (2018). STEM education as a GERM: Reviewing Australia's STEM discourse. In J. Zajda (Ed.), Globalisation and education reforms (pp. 79-91). Dordrecht, The Netherlands: Springer.

Coakes, S. J., \& Steed, L. G. (1999). SPSS: Analysis without anguish. Sydney, Australia: John Wiley and Sons.

Fredricks, J., Blumenfeld, P., \& Paris, A. (2004). School engagement: Potential of the concept, state of the evidence. Review of Educational Research. 74(1), 59-109.

Hair, J., Black, W., Babin, B., \& Anderson, R. (2014). Multivariate data analysis (7th ed.). Upper Saddle River, NJ: Prentice Hall.

Hobbs, L., Jakab, C., Millar, V., Prain, V., Redman, C., Speldewinde, C. \& van Driel, J. (2017). Girls'futureOur future: The Invergowrie Foundation STEM report. Melbourne, Australia: Invergowrie Foundation.

Hobbs, L., Clark, J. C., \& Plant, B. (2018). Successful students-STEM program: Teacher learning through a multifaceted vision for STEM education. In R. Jorgensen \& K. Larkin (Eds.) STEM education in the junior secondary (pp. 133-168). Singapore: Springer.

Kennedy, J., Lyons, T., \& Quinn, F. (2014). The continuing decline of science and mathematics enrolments in Australian high schools. Teaching Science, 60(2), 34.

Kim, A. Y., Sinatra, G. M., \& Seyranian, V. (2018). Developing a STEM identity among young women: A social identity perspective. Review of Educational Research, 88(4), 589-625.

Kozoll, R. H., \& Osborne, M. D. (2004). Finding meaning in science: Lifeworld, identity, and self. Science Education, 88, 157-181

Kraft, P., Rise, J., Sutton, S., \& Røysamb, E. (2005). Perceived difficulty in the theory of planned behaviour: Perceived behavioural control or affective attitude? British Journal of Social Psychology, 44(3), 479-496.

Leaper, C., Farkas, T., \& Brown, C. S. (2012). Adolescent girls' experiences and gender-related beliefs in relation to their motivation in math/science and English. Journal of Youth and Adolescence, 41(3), 268282.

Marginson, S., Tytler, R., Freeman, B., \& Roberts, K. (2013). STEM: Country comparisons: International comparisons of science, technology, engineering and mathematics (STEM). Melbourne, Australia: Australian Academy of Learned Academies.

Marks, H. M. (2000). Student engagement in instructional activity: Patterns in the elementary, middle, and high school years. American Educational Research Journal, 37(1), 153-184.

Matthews, J. S., Banerjee, M., \& Lauermann, F. (2014). Academic identity formation and motivation among ethnic minority adolescents: The role of the "Self" between internal and external perceptions of identity. Child Development, 85, 2355-2373.

McLeod, D. B. (1992). Research on affect in mathematics education: A reconceptualization. In D. A. Grouws (Ed.), Handbook of Research on Mathematics Teaching and Learning (pp. 575-596). New York, NY: MacMillan.

Metcalf, M. P. (2013). Assessment of an interactive internet program to educate children aged 7-9 about science, the brain and drugs. Creative Education, 4, 683-693.

Nadelson, L. S., Callahan, J., Pyke, P., Hay, A., Dance, M., \& Pfiester, J. (2013). Teacher STEM perception and preparation: Inquiry-based STEM professional development for elementary teachers. The Journal of Educational Research, 106(2), 157-168.

Naizer, G., Hawthorne, M. J., \& Henley, T. B. (2014). Narrowing the gender gap: Enduring changes in middle school students' attitude toward math, science and technology. Journal of STEM Education, 15(3), 29-34.

Office of the Chief Scientist. (2016). Australia's STEM Workforce. Canberra, Australia: Australian Government. Retrieved from https://www.chiefscientist.gov.au/2016/03/report-australias-stem-workforce/

Perez, R., Cromley, J. G., \& Kaplan, A. (2013). The role of identity development, values, and costs in college STEM retention. Journal of Educational Psychology, 106, 315-329. 
Pierce, R., Stacey, K., \& Barkatsas, A. N. (2007). A scale for monitoring students' attitudes to learning mathematics with technology. Computers and Education, 48(2), 285-300.

Polman, J. L., \& Miller, D. (2010). Changing stories: Trajectories of identification among African American youth in a science outreach apprenticeship. American Educational Research Journal, 47(4), 879-918.

Porter, L. W., \& Lawler, E. E. (1968). What job attitudes can tell us about employee motivation. Harvard Business Review, 46(1), 118-126.

Portz, S. (2015). The challenges of STEM Education. The Space Congress Proceedings, Paper 3. Retrieved from http://www.commons.erau/space-congress-proceedings/proceeding-2015-43rd/proceedings-2015$43 \mathrm{rd} / 3 /$

Price Waterhouse Coopers. (2015). Future-proofing Australia's workforce by growing skills in science, technology, engineering and maths (STEM). Retrieved from https://www.pwc.com.au/pdf/a-smart-movepwc-stem-report-april-2015.pdf

Radloff, J., \& Guzey, S. (2016). Investigating preservice STEM teacher conceptions of STEM education. Journal of Science Education and Technology, 25(5), 759-774.

Reid, P. T., \& Roberts, S. K. (2006). Gaining options: A mathematics program for potentially talented at-risk adolescent girls. Merrill-Palmer Quarterly, 52(2), 288-304.

Tabachnick, B. G., \& Fidell, L. S. (1996). Using multivariate statistics (3 ${ }^{\text {rd }}$ ed.). New York, NY: Harper Collins.

Timms, M., Moyle, K., Weldon, P., \& Mitchell, P. (2018). Challenges in STEM learning in Australian schools. Policy Insights, (7). Camberwell, Australia: Australian Council for Educational Research.

Tytler, R., Osborne, J., Williams, G., Tytler, K., \& Clark, J. C. (2008). Opening up pathways: Engagement in STEM across the primary secondary school transition. Canberra, Australia: Australian Department of Education, Employment and Workplace Relations.

Vasquez, J. A. (2015). STEM--Beyond the acronym. Educational Leadership, 72(4), 10-15.

Wang, M. T., \& Degol, J. (2013). Motivational pathways to STEM career choices: Using expectancy-value perspective to understand individual and gender differences in STEM fields. Developmental Review, 33(4), 304-340.

Watt, H. (2016). Promoting girls' and boys' engagement and participation in senior secondary STEM fields and occupational aspirations. In the proceedings of the ACER Research Conference 2016: Improving STEM Learning: What will it take? Brisbane, August 7-9 (pp. 34-44). Retrieved from http://research.acer. edu.au/cgi/viewcontent.cgi?article $=1285 \&$ context=research_conference

Weber, K. (2012). Gender differences in interest, perceived personal capacity, and participation in STEMrelated activities. Journal of Technology Education, 24(1), 18-33. 